\title{
QUEEN'S
UNIVERSITY
BELFAST
}

\section{Emergency department and hospital care prior to suicide: A population based case control study}

O'Neill, S., Graham, B., \& Ennis, E. (2019). Emergency department and hospital care prior to suicide: A population based case control study. Journal of Affective Disorders, 249, 366-370.

https://doi.org/10.1016/j.jad.2019.02.052

\section{Published in:}

Journal of Affective Disorders

\section{Document Version:}

Peer reviewed version

Queen's University Belfast - Research Portal:

Link to publication record in Queen's University Belfast Research Portal

\section{Publisher rights}

(c) 2018 Elsevier B.V. All rights reserved.

This manuscript version is made available under the CC-BY-NC-ND 4.0 license http://creativecommons.org/licenses/by-nc-nd/4.0/,which permits distribution and reproduction for noncommercial purposes, provided the author and source are cited

\section{General rights}

Copyright for the publications made accessible via the Queen's University Belfast Research Portal is retained by the author(s) and / or other copyright owners and it is a condition of accessing these publications that users recognise and abide by the legal requirements associated with these rights.

Take down policy

The Research Portal is Queen's institutional repository that provides access to Queen's research output. Every effort has been made to ensure that content in the Research Portal does not infringe any person's rights, or applicable UK laws. If you discover content in the Research Portal that you believe breaches copyright or violates any law, please contact openaccess@qub.ac.uk. 


\title{
Emergency department and hospital care prior to suicide: A population based case
}

\author{
control study
}

Authors: O’Neill, S.1, Graham, B.2 \& Ennis, E.1

1 Psychology Research Institute, Ulster University, Coleraine Campus BT52 1SA

2 Queen's Management School, Queen's University Belfast, BT9 5EE

\section{Abstract}

Background: High proportions of those who die by suicide in Northern Ireland (NI) are not known to mental health services, making it important to understand contact with the wider health services. Previous research has not examined the patterns of emergency department (ED) attendance and hospital admissions amongst those who have died by suicide in NI.

Objectives: The study objectives are to examine the relationships between ED attendances, hospital admissions, and death by suicide. Methods: A case control methodology was used, drawing on routinely collected administrative data on all deaths by suicide in Northern Ireland between 1/1/2012 and 31/12/2015. Each death was matched to 5 live controls, based on age and gender $(n=6630)$. Results: Death by suicide is associated with a recent ED attendance, with the highest odds for those who attended within the past three months (odds = $3.2,95 \% \mathrm{CI}=2.5-4.2$ ). Death by suicide is also associated with recent hospital admission, with the highest odds of death for admission within the past three months (odds $=6.6,95 \%$ 
$\mathrm{CI}=5.2-8.3$ ). The odds of suicide are also higher for those living in a more deprived or urban area. Limitations: The study is limited to administrative data. Conclusions: Staff in EDs and hospitals may have a role in suicide prevention. These findings again support the importance of addressing economic deprivation and other area level factors, such as contagion in suicide prevention strategies.

Keywords; suicide; emergency department; hospital admission; deprivation; urban

Our understanding of the risk factors associated with suicidal behaviour has advanced greatly, however it remains impossible to fully explain or predict the behaviour and current guidance advises against the use of risk assessment scales to determine treatment or care pathways (Chan et al., 2016; National Institute for Health and Care Excellence (NICE), 2011; Runeson et al., 2017; Quinlivan et al., 2016). At 16 per 100,000 population (Northern Ireland Statistics and Research Agency, 2017), Northern Ireland (NI) currently has the highest rate of suicide in the United Kingdom (UK) (Snowcroft, 2017) and this is believed to be as a result of the high levels of mental illness in the region and population exposure to trauma associated with conflict (Bunting et al., 2013; O’Neill et al., 2014a).

Although the majority of people who die by suicide are believed to meet the criteria for a mental illness (Franklin et al., 2016; O’Connor \& Nock, 2014), high proportions (72\%) of those who die by suicide in NI are not known to mental health services (O’Neill et al., 2014 b). In the period $2005-2015$ only $27 \%$ of the suicide deaths in NI were by individuals who had been in contact with mental health services in the year prior to death (Appleby et al., 2016). A study of over 1600 suicides in NI found that those who died by suicide were more 
likely to be male (O’Neill et al., 2014b) and to have lived in deprived areas (Bunting et al., 2018). Among suicide decedents known to mental health services, females were more likely than males to have increased their service use and males were more likely than females to have disengaged from services use prior to death (O’Neill et al., 2014b).

Past work has evaluated unanticipated death after acute care but such work has not evaluated patterns of usage of ED services among those who have died by suicide (Chang et al., 2017). There has to date been no examination of the patterns of usage of Emergency Department (ED) services amongst those who have died by suicide in NI. Evidence from the self-harm registry indicates that the rates of self-harm are generally around $0.30 \%$ (i.e. 373 per 100,000 - 377 per 100,000 for males and 371 per 100,000 for females) with variations by region, and this rate and other rates across Ireland and the U.K. being higher than those typically documented in other European countries (Corcoran et al., 2015; HSC Public Health Agency, 2016). Case control studies are required in order to appropriately assess the utility of health service use as a risk factor for suicide.

Findings from studies examining health service use prior to suicide demonstrate the importance of culture and context. In a sample of American Indians who lived on a reservation, people who died by suicide had less service contact than the control group (Mock et al., 1996). In a UK primary care sample there was no difference in between the group who died by suicide and the control group (Power et al., 1997). Data was extracted from general practice patient notes and psychiatric case notes where available, and was concerned with consultations, referrals to secondary care, medication and diagnoses (Power et al., 1997). In a Canadian sample, death by suicide was examined in relation to physician visits and other services such as emergency department visits, inpatient hospital separation and engagement with community mental health facilities (Morrison et al., 2011). Those who died by suicide 
were twice as likely to access healthcare prior to death, with the biggest differences being in relation to services other than physician visits (Morrison et al., 2011).

Asians who died of suicide without a past history of suicidal behaviour were more likely to have a pre-suicidal plan for the fatal suicide act and have received medical or surgical treatment in the past (Ho et al., 2014). Based on usage of the ED at Reykjavik in Iceland, Kvaran et al. (2015) showed number of visits to the ED to be an independent risk factor for suicide, adjusted for other known risk factors. The prevalence of four or more visits was $40 \%$ among cases compared to $10 \%$ among controls (Kvaran et al., 2015). These studies suggest that in certain contexts the ED may be a suitable setting for suicide prevention initiatives. However further examination is necessary to address some methodological issues and examine the associations between service use in the NI context. This study extends these findings by examining ED usage and hospital admissions among those who have died by suicide across NI and comparing this to a matched control group.

\section{Methodology}

\section{Data Sources and Matching}

A case control methodology was used to examine the relationship between health service use and death by suicide. Four datasets were extracted and linked to obtain the final set of variables for analysis. Data on deaths by suicide was obtained from the records held by the general registrar and matched to controls from general practitioner (GP) patient registers. Data on health service use was obtained from trust administrative systems including Emergency Department Systems, and Hospital Patient Administration systems. The multiple deprivation measures (MDM) and urban rural classifications were produced by the Northern Ireland Statistics Research Agency (NISRA, 2015, 2010). All NI health service users have a 
unique identifier (the Health and Care Number), which made it possible to link individual level data from across the healthcare system.

The data was extracted, anonymised, and linked by the Northern Ireland Honest Broker Service which provides secure access to anonymised Northern Ireland health service data for ethically approved studies (HSC Business Services Organisation, 2016). The study was approved by the Brighton and Sussex Research Ethics Committee (REC Reference:

16/LO/1293). All data analysis was carried out in the honest brokers secure 'safe haven' research environment, and all results were subject to statistical disclosure control. The use of the Honest Broker Service helps to ensure the researchers do not have access to identifiable patient information.

\section{Cases}

The study cases included all deaths by suicide in Northern Ireland between 1/1/2012 and $31 / 12 / 2015$, resulting in a total of 1105 cases. These included all deaths recorded by the general registrars office under ICD-10 codes of intentional self harm (ICD10: X60-X84, Y87.0) and events of undetermined intent (ICD10: Y10-Y34, Y87.2). The inclusion of death by events of undetermined intent is consistent with the methodology adopted for measuring official suicide statistics (NISRA, 2012), and helps to prevent undercounting deaths by suicide. In total there were 374 deaths by poisoning and self harm with undetermined intent in the time period. The most recent year of data was excluded as it can take up to a year for the coroner's investigation to be completed and recorded (NISRA, 2012).

\section{Controls}

Each case was matched by age (the closest match within two years) and gender to 5 controls who were alive at the date of death of the case, resulting in 5525 controls, and a total of 6630 records. The control group was obtained from the general practitioner (GP) patient registers, 
which holds details of all people registered with a GP in Northern Ireland. The case control matching was carried out using SPSS.

\section{Variables}

The focal variables for this study were the use of health services prior to death for the case group, and service use prior to the matched date of death for the control group. We focus specifically on the use of emergency department services and hospital admissions. These are measured as binary variables indicating the time band within which the most recent contact with the service occurred. The following time bands were used: $>0-\leq 3$ months, $>3-\leq 6$ months, $>6-\leq 9$ months, $>9-\leq 12$ months, $>12-\leq 24$ months, and no contact within 24 months.

We also controlled for multiple deprivation, which was measured using the MDM (multiple deprivation measure) of the area within which the person lived, matched using the individual's postcode. The MDM is a composite measure made up of 7 domains measuring health; employment; proximity to services; income; living environment; crime and disorder; and education (NISRA, 2010). In total, 52 indicators are used to construct the area level MDM (NISRA, 2010). The Northern Ireland MDM has been widely used in prior research (e.g. Bunting et al., 2018). The first decile is made up of the $10 \%$ of the population living in the most deprived areas, and the tenth decile as the $10 \%$ of the population living in the least deprived areas. Ten of the cases and 49 of the controls could not be matched to a MDM due to incorrect postcodes. Rurality was measured based on the 2015 settlement classification (NISRA, 2015), matched using the individuals postcode.

\section{Statistical Analysis}

We calculated frequencies and percentages for each of the variables included in the analysis for both case and control groups. Conditional logistic regression was used to examine the relationships between health service use and death by suicide. The crude model focuses on 
the bivariate relationships between each variable and death by suicide. We then built two further models, each examining the relationship between the use of each service and death by suicide, whilst controlling for deprivation and rurality. The final full model included all service use variables, and controlled for deprivation and rurality. In each model, the reference category for health service use was 'no service use in the past 24 months'. The reference category for deprivation was the first decile, and rural areas for the rurality variable. The statistical analysis was carried out using the $\mathrm{R}$ statistical programming language $(\mathrm{R}$ Foundation, 2017).

\section{Results}

\section{Descriptive Statistics}

Table 1 shows that the majority of both the case and control groups had not attended an ED in the two years prior to death by suicide. $32.5 \%$ of people who died by suicide attended the ED department in the 24 months prior to death, compared to $16.9 \%$ of those in the control group. Higher ED attendances are observed in the case group across all time bands, but in particular in the three months prior to death, with $12.9 \%$ of the case group attending the ED in the three months prior to death compared to $3.3 \%$ of the control group. A similar pattern is observed when comparing the percentage of cases and controls who were admitted to hospital, with $41.9 \%$ of the case group having a hospital admission in the 24 months prior to death, compared with $14.3 \%$ in the control group. Almost one in five of those who died by suicide had a hospital admission in the three months prior to death, compared with only $3.8 \%$ of those in the control group. In both the case and control groups, the majority of people did not have a hospital admission in the 24 months prior to death. Overall, death by suicide is more common in the most deprived areas, with $21.0 \%$ of the case group living in the most deprived areas compared to $10.7 \%$ of the control group. The results show that a higher 
percentage of the case group live in urban areas $(72.8 \%)$, compared to the control group $(63.0 \%)$. Suicide is most frequent between the ages of 20 and 54, and in males, who account for $75.75 \%$ of deaths by suicide.

\section{Emergency Department Attendances}

These results presented in the crude model in table 2 show that the people who died by suicide are significantly more likely to have attended the ED across all of the time bands, compared to the control group. The same pattern emerges in the adjusted model, which controls for deprivation and rurality. However, when prior admissions are included in the full model, ED attendances in the previous $>6-\leq 9$ months and $>9-\leq 12$ months are no longer significant. In the full model the odds of being in the death by suicide group are highest for people who attended the ED department in the three months prior to the date of death of the person who died (odds $=3.2,95 \% \mathrm{CI}=2.5-4.2)$.

\section{Hospital Admissions}

The results of the crude model show that people who died by suicide are significantly more likely to have been admitted to hospital across all time bands, compared to the control group. Hospital admission in all of the time bands remains significant across the model controlling for deprivation and rurality, and in the full model. In the full model, the odds of death by suicide are highest for admissions in the $>0-\leq 3$ and $>3-\leq 6$ months prior to the date of death of the person who died by suicide (odds $=6.6$ and $4.4,95 \% \mathrm{CI}=5.2-8.3$ and $3.2-6.0$ ).

\section{Deprivation and Rurality}

Across all models, people who died by suicide are significantly more likely to live in a more deprived area. Furthermore, people who died by suicide are significantly more likely to have lived in urban areas. This relationship remains significant in both the adjusted (odds $=1.4$, $95 \% \mathrm{CI}=1.2-1.6)$ and full models (odds $=1.3,95 \% \mathrm{CI}=1.1-1.6)$. 


\section{Discussion}

This study provides the first analysis of health service use data and suicide in NI, based on 1105 records of those who died by suicide over a three year period, matched to a live control group. These findings show that about a third of those who died by suicide had attended an ED prior to death and $40 \%$ had been admitted to hospital. The higher proportions in the deceased group with hospital contact in the months leading up to the death is striking. The results demonstrate a significant elevated risk of death in the 3 months period post ED attendance. Whilst we do not have data on the presenting issue, admission to the ED may be more likely in these cases to be related to self-harm or suicide attempt, given that suicide attempt is a strong predictor of death by suicide (De Moore and Robertson, 1996; Hawton et al., 2003; Jenkins et al., 2002, O'Connor \& Nock, 2014).

In terms of hospital admission, for which there may be a wider variety of reasons (e.g. acute illness or injury, scheduled surgery), there is an elevated risk in the six-month period after admission. A previous study found that people who attempted suicide using overdose method had a higher number of psychiatric ward admissions than those who used other methods (Ho et al., 2016). The evidence demonstrates that people with physical health problems have an increased risk of self-harm and suicide (Singhal et al., 2014). Indeed in an analysis of coronial data on suicide deaths in NI, physical illness was more likely to be recorded as a contributing factor in the suicides of older people (O'Neill et al., 2018). Contact with clinicians, regardless of the presenting issue, provides an opportunity for compassionate interactions to assess mental health and suicidal thoughts. Accurate suicide assessment requires assessment of affect (e.g. depressed mood), behaviour during the suicide attempt and cognition (e.g. negative thought) (Harris et al., 2015). There is therefore an argument for the 
training of all health care professionals, particularly those who work in EDs and hospitals, in brief, evidence informed, suicide prevention strategies (such as safety planning, Stanley and Brown, 2012). Those who use secondary health care (i.e. mental health or psychiatric services) are also likely to access primary care services, therefore supporting the need for staff training and intervention delivery in primary care (Pearson, et al., 2009).

The fact that almost twice the proportion of those who died by suicide lived in deprived areas, compared with the matched cases who had not died, is also notable. In addition, there was a higher proportion of those who died by suicide who lived in urban compared with rural areas $(72.8 \%$ compared with $26.3 \%)$. This again demonstrates the strong associations between suicide and deprivation in NI, and the association with urbanicity, which have been reported previously (Bunting et al., 2018; O’Reilly et al., 2008). This study demonstrates that these variables are independent risk factors and do not account for the associations with health service use prior to death. Economic deprivation is a legacy of the NI civil conflict, and previous research in the region has demonstrated the links between conflict-related trauma exposure and suicidal behaviour (O’Neill et al., 2014) and self-harm in young people (O’Connor et al., 2014). These findings again support the importance of addressing economic deprivation and other area level factors, such as contagion in suicide prevention strategies (Bunting et al., 2018). Contagion is where whereby exposure to suicide can increase suicide risk. In addition, it is important to target suicide prevention initiatives and mental health services in the most deprived areas of NI.

The majority of the deceased had not attended the ED (67.5\%), and had not had a hospital admission (58.1\%). The results also provide evidence that many of those who die by suicide have not had recent contact with health, or indeed mental health services, other than their GP (O’Neill et al., 2014; Power et al., 1997; Stark et al., 2012; Luoma et al., 2002). This 
further suggests that many of those who die by suicide do not recognise the signs of mental illness or seek support for suicidal thoughts. These findings also support the use of carefully designed anti stigma campaigns and efforts to encourage people to disclose suicidal ideation and seek treatment and support. Broader education in relation to the warning signs for suicidal behaviour and how to support people to access services, is also recommended.

\section{Limitations}

There are a number of limitations that need to be considered when interpreting the results from this study. This study did not include primary care use, and this is a main service used prior to death in NI (O'Neill et al., 2014b). Although we draw on GP registration data to enable the case-control matching, we do not have data on actual GP service use. Analyses focused on recency of attendance and did not consider frequency of ED attendances and hospital admissions, which should also be investigated. Data was not available on the reason for admission or attendance, the presenting issue or length of stay; indeed, many people who attempt suicide, or self-harm may not attend the ED. There are numerous complex factors that

interact to increase risk of death by suicide, that were not considered in this study e.g. including financial strain (Choo et al., 2018), ethnic differences (Mak et al., 2015), choice of method (Choo et al., 2017), symptoms of psychotic illness, borderline personality disorder, and psychosomatic illness (Choo et al., 2014). It is important that data on suicide deaths in NI is collected in a systematic way so that standardised data is available on key variables to provide a fuller understanding of the associations between mental and physical health problems, situational crises and suicidal behaviour. At present some data is collected with regards to suicide but detailed information regarding the circumstances of death is only collected if the coroner holds an inquest. In addition, broader social and contextual factors, such as the history 
of violence and trauma exposure need to be taken into consideration in order to address the high rates of suicide in the region. As the study draws on data from one region within the United Kingdom, caution should be taken when generalising the results to other contexts.

\section{References}

Appleby L, et al. (2016). The National Confidential Inquiry into Suicide and Homicide by People with Mental Illness. Retrieved from:

http://research.bmh.manchester.ac.uk/cmhs/research/centreforsuicideprevention/nci/rep orts/2016-report.pdf

Bunting BP, et al. (2013). Trauma associated with civil conflict and posttraumatic stress disorder: evidence from the Northern Ireland study of health and Stress. Journal of Traumatic Stress, 26(1), 134-141.

Bunting BP, et al. (2018). Death by suicide at the Ward level in Northern Ireland. Psychological Medicine, 48(8), 1375-1380.

Chan MK, et al. (2016). Predicting suicide following self-harm: systematic review of risk factors and risk scales. British Journal of Psychiatry, 209, 277-283.

Chang, B.P., Pany, M.J. and Obermeyer, Z., 2017. Early death after emergency department discharge in patients with psychiatric illness. The American Journal of Emergency Medicine, 35(5), 784-786.

Choo CC et al. (2018) Thematic Analysis of Medical Notes Offers Preliminary Insight into Precipitants for Asian Suicide Attempters: An Exploratory Study. Int J Environ Res Public Health, 15(4). 
Choo CC et al (2017) Prediction of Lethality in Suicide Attempts: Gender Matters. Omega (Westport), 1, 30222817725182.

Choo C et al (2014) Cluster analysis reveals risk factors for repeated suicide attempts in a multiethnic Asian population. Asian J Psychiatry, 8, 38-42.

Corcoran P, et al. (2015). Hospital-Treated Deliberate Self-Harm in the Western Area of Northern Ireland. Crisis, 12, 1-8.

De Moore, G. \& Robertson, A. (1996). Suicide in the 18 years after deliberate self-harm. British Journal of Psychiatry, 169, 489-494.

Franklin JC, et al. (2017). Risk factors for suicidal thoughts and behaviors: A meta-analysis of 50 years of research. Psychological Bulletin, 143, 187-232.

Hawton K, et al. (2003). Suicide following deliberate self-harm : long-term follow-up of patients who presented to a general hospital Suicide following deliberate self-harm : long-term follow-up of patients who presented to a general hospital. British Journal of Psychiatry, 182, 537-542.

Harris KM, et al. (2015) The ABC's of Suicide Risk Assessment: Applying a Tripartite Approach to Individual Evaluations. PLoS One, 10(6):e 0127442.

Ho RC, et al. (2014). Elderly suicide with and without a history of suicidal behaviour: implications for suicide prevention and management. Archives of Suicide Research, 18(4), 363-75.

Ho CS, et al. (2016). Profile differences between overdose and non-overdose suicide attempts in a multi-ethnic Asian society. BMC Psychiatry, 16(1), 379.

HSC Public Health Agency (2016). Northern Ireland Registry of Self-harm Regional Threeyear report, 2012/13 to 2014/15. Retrieved from; 
http://www.publichealth.hscni.net/sites/default/files/NIRSH\%203\%20year\%20report\% 2014.11.06.pdf

HSC Business Services Organisation (2016). Honest Broker Service. Retrieved from; http://www.hscbusiness.hscni.net/services/2454.htm (accessed 9.18.16).

Jenkins GR, et al. (2002). Suicide rate 22 years after parasuicide: cohort study. BMJ, 325, 1155.

Kapur N, et al. (2013). Psychiatric in-patient care and suicide in England, 1997 to 2008: a longitudinal study. Psychological Medicine, 43(1), 61-71.

Kvaran RB, et al. (2015). Number of visits to the emergency department and risk of suicide: a population- based case-control study. BMC Public Health, 15, 227. https://doi.org/10.1186/s12889-015-1544-5

Luoma JB, et al. (2002). Contact with mental health and primary care providers before suicide: a review of the evidence. American Journal of Psychiatry, 159, 909916.

Mak KK, et al. (2015) Ethnic differences in suicide behavior in Singapore. Transcult Psychiatry, 52(1), 3-17.

Mock CN, et al. (1996). Health care utilization as a marker for suicidal behavior on an American Indian reservation. Journal of General Internal Medicine, 11, 519-24.

Morrison, K.B. \& Laing, L. (2011). Adults' use of health services in the year before death by suicide in Alberta. Health Rep., 22, 15-22.

National Institute for Health and Care Excellence (NICE) (2011). Self-harm in over 8s: longterm management. Retrieved from: https://www.nice.org.uk/guidance/CG133/chapter/1-Guidance\#psychosocialassessment-in-community-mental-health-services-and-other-specialist-mental-health 
Northern Ireland Statistics and Research Agency (NISRA) (2017). Suicide statistics. Retrieved from; https://www.nisra.gov.uk/publications/suicide-statistics

NISRA (2015). Settlement 2015 Documentation. Retrieved from; https://www.nisra.gov.uk/publications/settlement-2015-documentation (accessed 4.15.18).

NISRA (2012). Suicide statistics in Northern Ireland: Impact of Time Taken to Investigate the Death. Retrieved from: https://www.nisra.gov.uk/publications/suicide-reports

NISRA (2010). Northern Ireland Multiple Deprivation Measure 2010. Retrieved from: https://www.nisra.gov.uk/statistics/deprivation/northern-ireland-multiple-deprivationmeasure-2010-nimdm2010

O’Connor, RC \& Nock, MK. (2014). The psychology of suicidal behaviour. Lancet Psychiatry, 1, 73-85.

O'Neill S, et al. (2018). Factors associated with suicide in four age groups: A population based study. Archives of Suicide Research, 22(1), 128-138.

O'Neill S, et al. (2014a). Patterns of suicidal ideation and behavior in Northern Ireland and associations with conflict related trauma. PLoS One, 19(3), e91532.

O'Neill S, et al. (2014b). Characteristics of deaths by suicide in Northern Ireland from 2005 to 2011 and use of health services prior to death. Journal of Affective Disorders, 168, $466-471$.

O'Connor RC, et al. (2014). Adolescent self-harm: a school-based study in Northern Ireland. Journal of Affective Disorders., 159, 46-52.

O'Reilly D, et al. (2008). Area factors and suicide: 5-year follow-up of the Northern Ireland population. The British Journal of Psychiatry 192, 106-111. 
Pearson A, et al., (2009). Primary care contact prior to suicide in individuals with mental illness. British Journal of General Practice, 59(568), 825-832.

Power K, et al. (1997). Case-control study of GP attendance rate by suicide cases with or without a psychiatric history. Br J Gen Practice, 47, 211-5.

Quinlivan L, et al. (2016). Which are the most useful scales for predicting repeat self-harm? A systematic review evaluating risk scales using measures of diagnostic accuracy. BMJ Open, 6(2), e009297.

Runeson B, et al. (2017). Instruments for the assessment of suicide risk: A systematic review evaluating the certainty of the evidence. Plos One, 12, e0180292. doi: 10.1371/journal.pone.0180292

Snowcroft, E. (2017). Samaritans; Suicide Statistics Report 2017. Retrieved from: https://www.samaritans.org/sites/default/files/kcfinder/files/Suicide_statistics_report_2 017_Final.pdf

Singhal A, et al. (2014). Risk of self-harm and suicide in people with specific psychiatric and physical disorders: comparisons between disorders using English national record linkage. Journal of the Royal Society of Medicine, 107(5), 194-204.

Stanley, B. \& Brown, GK. (2012). Safety planning intervention: A brief intervention to mitigate suicide risk. Cognitive and Behavioural Practice, 19(2), 256-264.

Stark CR, et al. (2012). Service contacts prior to death in people dying by suicide in the Scottish Highlands. Rural and Remote Health, 12(3), 1876.

R Foundation (2017). The R project for statistical computing. Retrieved from; https:/www.rproject.org/ 

Descriptive Statistics

Table 1: Descriptive Statistics

\begin{tabular}{|c|c|c|c|c|c|}
\hline Variable & $\begin{array}{l}\text { Case } \\
(n)\end{array}$ & $\begin{array}{l}\text { Control } \\
\text { (n) }\end{array}$ & Total (n) & $\begin{array}{l}\text { Case } \\
(\%)\end{array}$ & $\begin{array}{l}\text { Control } \\
(\%)\end{array}$ \\
\hline \multicolumn{6}{|l|}{ Most Recent ED Attendance } \\
\hline$>0-\leq 3$ months & 142 & 181 & 323 & 12.9 & 3.3 \\
\hline$>3-\leq 6$ months & 55 & 153 & 208 & 5.0 & 2.8 \\
\hline$>6-\leq 9$ months & 45 & 142 & 187 & 4.1 & 2.6 \\
\hline$>9-\leq 12$ months & 33 & 121 & 154 & 3.0 & 2.2 \\
\hline$>12-\leq 24$ months & 84 & 334 & 418 & 7.6 & 6.0 \\
\hline None within 24 months & 746 & 4594 & 5340 & 67.5 & 83.1 \\
\hline ED attendance within 24 months & 359 & 931 & 1290 & 32.5 & 16.9 \\
\hline \multicolumn{6}{|c|}{ Most Recent Hospital Admission } \\
\hline$>0-\leq 3$ months & 217 & 209 & 426 & 19.6 & 3.8 \\
\hline$>3-\leq 6$ months & 80 & 127 & 207 & 7.2 & 2.3 \\
\hline$>6-\leq 9$ months & 53 & 128 & 181 & 4.8 & 2.3 \\
\hline$>9-\leq 12$ months & 41 & 77 & 118 & 3.7 & 1.4 \\
\hline$>12-\leq 24$ months & 72 & 250 & 322 & 6.5 & 4.5 \\
\hline None within 24 months & 642 & 4734 & 5376 & 58.1 & 85.7 \\
\hline $\begin{array}{l}\text { Hospital admission within } 24 \\
\text { months }\end{array}$ & 463 & 791 & 1254 & 41.9 & 14.3 \\
\hline \multicolumn{6}{|l|}{ Multiple Deprivation Measure, decile } \\
\hline 1 (most deprived) & 230 & 587 & 817 & 21.0 & 10.7 \\
\hline 2 & 147 & 563 & 710 & 13.4 & 10.3 \\
\hline 3 & 122 & 558 & 680 & 11.1 & 10.2 \\
\hline 4 & 121 & 606 & 727 & 11.1 & 11.1 \\
\hline 5 & 97 & 540 & 637 & 8.9 & 9.9 \\
\hline 6 & 94 & 548 & 642 & 8.6 & 10.0 \\
\hline 7 & 81 & 503 & 584 & 7.4 & 9.2 \\
\hline 8 & 101 & 558 & 659 & 9.2 & 10.2 \\
\hline 9 & 50 & 537 & 587 & 4.6 & 9.8 \\
\hline 10 (least deprived) & 52 & 476 & 528 & 4.7 & 8.7 \\
\hline Urban Area & 804 & 3483 & 4287 & 72.8 & 63.0 \\
\hline Rural Area & 291 & 1991 & 2282 & 26.3 & 36.0 \\
\hline \multicolumn{6}{|l|}{ Age, years } \\
\hline 10 to 19 & 55 & 364 & 419 & 4.98 & 6.59 \\
\hline $20-24$ & 111 & 472 & 583 & 10.05 & 8.54 \\
\hline $25-29$ & 131 & 637 & 768 & 11.86 & 11.53 \\
\hline $30-34$ & 124 & 581 & 705 & 11.22 & 10.52 \\
\hline $35-39$ & 114 & 587 & 701 & 10.32 & 10.62 \\
\hline $40-44$ & 110 & 609 & 719 & 9.95 & 11.02 \\
\hline $45-49$ & 129 & 583 & 712 & 11.67 & 10.55 \\
\hline $50-54$ & 111 & 539 & 650 & 10.05 & 9.76 \\
\hline $55-59$ & 74 & 406 & 480 & 6.70 & 7.35 \\
\hline $60-64$ & 62 & 286 & 348 & 5.61 & 5.18 \\
\hline
\end{tabular}




\begin{tabular}{llllll}
$65-69$ & 38 & 220 & 258 & 3.44 & 3.98 \\
$70-74$ & 20 & 114 & 134 & 1.81 & 2.06 \\
over75 & 26 & 127 & 153 & 2.35 & 2.30 \\
Gender & & & & & \\
Female & 268 & 1340 & 1608 & 24.25 & 24.25 \\
Male & 837 & 4185 & 5022 & 75.75 & 75.75 \\
\hline
\end{tabular}


Table 2: Conditional Logistic Regression Models

\begin{tabular}{|c|c|c|c|c|c|c|c|c|}
\hline \multirow[t]{2}{*}{ Variable } & \multicolumn{2}{|l|}{ Crude $^{\mathrm{a}}$} & \multicolumn{2}{|c|}{ Adjusted - ED ${ }^{b}$} & \multicolumn{2}{|c|}{ Adjusted - AD ${ }^{c}$} & \multicolumn{2}{|c|}{ Full Models ${ }^{d}$} \\
\hline & Odds & $\begin{array}{l}95 \% \\
\text { CI }\end{array}$ & Odds & $\begin{array}{l}95 \% \\
\text { CI }\end{array}$ & Odds & $\begin{array}{l}95 \% \\
\text { CI }\end{array}$ & Odds & $\begin{array}{l}95 \% \\
\text { CI }\end{array}$ \\
\hline \multicolumn{9}{|c|}{ Most Recent ED Attendance } \\
\hline$>0-\leq 3$ months & $4.8 * * *$ & $\begin{array}{l}3.8- \\
6.0\end{array}$ & $5.2 * * *$ & $\begin{array}{l}4.1- \\
6.6\end{array}$ & & & $3.2 * * *$ & $\begin{array}{l}2.5- \\
4.2\end{array}$ \\
\hline$>3-\leq 6$ months & $2.2 * * *$ & $\begin{array}{l}1.6- \\
3.0\end{array}$ & $2.4 * * *$ & $\begin{array}{l}1.7- \\
3.3\end{array}$ & & & $1.7 * *$ & $\begin{array}{l}1.2- \\
2.4\end{array}$ \\
\hline$>6-\leq 9$ months & $2.0 * * *$ & $\begin{array}{l}1.4- \\
2.7\end{array}$ & $2.0 * * *$ & $\begin{array}{l}1.4- \\
2.8\end{array}$ & & & 1.3 & $\begin{array}{l}0.9- \\
1.9\end{array}$ \\
\hline $\begin{array}{l}>9-\leq 12 \\
\text { months }\end{array}$ & $1.7^{*}$ & $\begin{array}{l}1.1- \\
2.5\end{array}$ & $1.7^{*}$ & $\begin{array}{l}1.1- \\
2.5\end{array}$ & & & 1.4 & $\begin{array}{l}0.9- \\
2.1\end{array}$ \\
\hline $\begin{array}{l}>12-\leq 24 \\
\text { months }\end{array}$ & $1.5 * * *$ & $\begin{array}{l}1.2- \\
2.0\end{array}$ & $1.6 * * *$ & $\begin{array}{l}1.2- \\
2.0\end{array}$ & & & $1.4^{*}$ & $\begin{array}{l}1.0- \\
1.8\end{array}$ \\
\hline \multicolumn{9}{|c|}{ Most Recent Hospital Admission } \\
\hline$>0-\leq 3$ months & $8.4 * * *$ & $\begin{array}{l}6.7- \\
10.4\end{array}$ & & & $8.2 * * *$ & $\begin{array}{l}6.5- \\
10.3\end{array}$ & $6.6^{* * *}$ & $\begin{array}{l}5.2- \\
8.3\end{array}$ \\
\hline$>3-\leq 6$ months & $5.0 * * *$ & $\begin{array}{l}3.7- \\
6.8\end{array}$ & & & $4.9 * * *$ & $\begin{array}{l}3.6- \\
6.7\end{array}$ & $4.4 * * *$ & $\begin{array}{l}3.2- \\
6.0\end{array}$ \\
\hline$>6-\leq 9$ months & $3.4 * * *$ & $\begin{array}{l}2.4- \\
4.8\end{array}$ & & & $3.2 * * *$ & $\begin{array}{l}2.3- \\
4.6\end{array}$ & $3.0 * * *$ & $\begin{array}{l}2.0- \\
4.2\end{array}$ \\
\hline $\begin{array}{l}>9-\leq 12 \\
\text { months }\end{array}$ & $4.6^{* * *}$ & $\begin{array}{l}3.1- \\
6.8\end{array}$ & & & $4.3 * * *$ & $\begin{array}{l}2.8- \\
6.5\end{array}$ & $4.0 * * *$ & $\begin{array}{l}2.6- \\
6.1\end{array}$ \\
\hline $\begin{array}{l}>12-\leq 24 \\
\text { months }\end{array}$ & $2.5 * * *$ & $\begin{array}{l}1.8- \\
3.3\end{array}$ & & & $2.4 * * *$ & $\begin{array}{l}1.8- \\
3.2\end{array}$ & $2.1 * * *$ & $\begin{array}{l}1.6- \\
2.9\end{array}$ \\
\hline \multicolumn{9}{|c|}{ Multiple Deprivation Measure (decile) } \\
\hline 2 & $0.67 * * *$ & $\begin{array}{l}0.5- \\
0.8\end{array}$ & $0.6 * * *$ & $\begin{array}{l}0.5- \\
0.8\end{array}$ & $0.7 *$ & $\begin{array}{l}0.6- \\
0.9\end{array}$ & $0.7 * *$ & $\begin{array}{l}0.5- \\
0.8\end{array}$ \\
\hline 3 & $0.6 * * *$ & $\begin{array}{l}0.4- \\
0.7\end{array}$ & $0.5 * *$ & $\begin{array}{l}0.4- \\
0.7\end{array}$ & $0.6 * * *$ & $\begin{array}{l}0.5- \\
0.8\end{array}$ & $0.6 * * *$ & $\begin{array}{l}0.4- \\
0.8\end{array}$ \\
\hline 4 & $0.5^{* * *}$ & $\begin{array}{l}0.4- \\
0.6\end{array}$ & $0.5 * * *$ & $\begin{array}{l}0.4- \\
0.7\end{array}$ & $0.6^{* * *}$ & $\begin{array}{l}0.4- \\
0.8\end{array}$ & $0.5^{* * *}$ & $\begin{array}{l}0.4- \\
0.7\end{array}$ \\
\hline 5 & $0.5 * * *$ & $\begin{array}{l}0.3- \\
0.6\end{array}$ & $0.5 * * *$ & $\begin{array}{l}0.4- \\
0.6\end{array}$ & $0.5 * * *$ & $\begin{array}{l}0.4- \\
0.7\end{array}$ & $0.5 * * *$ & $\begin{array}{l}0.4- \\
0.7\end{array}$ \\
\hline 6 & $0.4 * * *$ & $\begin{array}{l}0.3- \\
0.6\end{array}$ & $0.5 * * *$ & $\begin{array}{l}0.3- \\
0.6\end{array}$ & $0.5 * * *$ & $\begin{array}{l}0.4- \\
0.7\end{array}$ & $0.4 * * *$ & $\begin{array}{l}0.3- \\
0.6\end{array}$ \\
\hline 7 & $0.4 * * *$ & $\begin{array}{l}0.3- \\
0.5\end{array}$ & $0.4 * * *$ & $\begin{array}{l}0.3- \\
0.6\end{array}$ & $0.5 * * *$ & $\begin{array}{l}0.3- \\
0.6\end{array}$ & $0.4 * * *$ & $\begin{array}{l}0.3- \\
0.6\end{array}$ \\
\hline 8 & $0.5 * * *$ & $\begin{array}{l}0.4- \\
0.6\end{array}$ & $0.5 * * *$ & $\begin{array}{l}0.4- \\
0.7\end{array}$ & $0.5 * * *$ & $\begin{array}{l}0.4- \\
0.7\end{array}$ & $0.5 * * *$ & $\begin{array}{l}0.4- \\
0.7\end{array}$ \\
\hline 9 & $0.2 * * *$ & $\begin{array}{l}0.2- \\
0.3\end{array}$ & $0.3 * * *$ & $\begin{array}{l}0.2- \\
0.4\end{array}$ & $0.3 * * *$ & $\begin{array}{l}0.2- \\
0.4\end{array}$ & $0.3 * * *$ & $\begin{array}{l}0.2- \\
0.4\end{array}$ \\
\hline $\begin{array}{l}10 \text { (least } \\
\text { deprived) }\end{array}$ & $0.3 * * *$ & $\begin{array}{l}0.2- \\
0.4\end{array}$ & $0.3 * * *$ & $\begin{array}{l}0.2- \\
0.4\end{array}$ & $0.3 * * *$ & $\begin{array}{l}0.2- \\
0.4\end{array}$ & $0.3 * * *$ & $\begin{array}{l}0.2- \\
0.4\end{array}$ \\
\hline Urban Area & $1.6^{* * *}$ & $\begin{array}{l}1.4- \\
1.8\end{array}$ & $1.4 * * *$ & $\begin{array}{l}1.2- \\
1.6\end{array}$ & $1.3^{* *}$ & $\begin{array}{l}1.1- \\
1.6\end{array}$ & $1.3^{* *}$ & $\begin{array}{l}1.1- \\
1.6\end{array}$ \\
\hline
\end{tabular}


${ }^{a}$ Adjusted for age and gender based on matching criteria.

${ }^{\mathrm{b}}$ The relationship between the most recent ED attendance and death by suicide, adjusted for age, gender, deprivation and rurality.

${ }^{\mathrm{c}}$ The relationship between the most recent hospital admission and death by suicide, adjusted for age, gender, deprivation and rurality.

${ }^{\mathrm{d}}$ The full model showing the relationship between the most recent ED attendance and hospital attendance, controlling for age, gender, deprivation and rurality. 